\title{
Política educacional, pobreza e educação: retrato do atendimento aos estudantes beneficiários do Programa Bolsa Família no Paraná*
}

\section{Educational policy, poverty and education: a portrait of the assistance to students who are beneficiaries of the Bolsa Família Program in Paraná}

\author{
Adriana Dragone Silveira** \\ Gabriela Schneider* $^{* *}$
}

\begin{abstract}
RESUMO
Este artigo apresenta uma leitura inicial sobre como estão distribuídos os estudantes beneficiários do Programa Bolsa Família no estado do Paraná a partir dos dados do Banco do Sistema Presença de 2014, cotejados com o Censo Escolar do mesmo ano. Para a construção de um mapeamento sobre as condições de oferta escolar, considerou-se as condições que têm sido asseguradas aos estudantes, tomando-se, em especial, informações quanto às condições de trabalho docente (contrato de trabalho e formação docente) e às condições de infraestrutura da escola (biblioteca, internet, banda larga, laboratório de informática e quadra de esporte). O objetivo é problematizar as condições de equidade na produção da política educacional, partindo-se do pressuposto de que o enfrentamento das desigualdades educacionais no Brasil implica reconhecimento de que a população pobre está na escola
\end{abstract}

DOI: $10.1590 / 0104-4060.51391$

* Este artigo é resultado da pesquisa "A efetividade da política educacional na garantia do direito à educação da população em situação de pobreza", financiada pela Secretaria de Educação Continuada, Alfabetização, Diversidade e Inclusão - Secadi/MEC no âmbito do Programa Educação, Pobreza e Desigualdades Sociais.

** Universidade Federal do Paraná. Setor de Educação. Curitiba, Paraná, Brasil. Rua General Carneiro, n 460. Centro. CEP: 80060-150.E-mail: adrianadragone@ufpr.br; gabrielaschneider@ufpr.br. 
pública e de que o trabalho escolar tem implicações objetivas para a construção de uma experiência inclusiva e de qualidade para o percurso escolar desta população.

Palavras-chave: Programa Bolsa Família. Direito à educação. Condições de qualidade. Política educacional.

\begin{abstract}
This article presents an initial reading about how the beneficiaries of the Bolsa Família Program in the state of Paraná are distributed, based on data of 2014 from the System Bank Presença, compared to the School Census of the same year. This allows for the construction of a map about the conditions of school's offerings. For this, the conditions assured to the students have been considered, from information taken about the working conditions of the teachers (work contract and teacher training), and the state of the schools' infrastructure, (library, internet access, broadband connection, computer lab and sports court). The objective is to problematize the conditions of equity in the construction of educational policy, starting from the assumption that confronting the educational inequalities in Brazil imply recognizing that the poor are in the public scholar system and also that schoolwork has objective significance for the construction of an inclusive and qualitative experience for the educational journey of this population.
\end{abstract}

Keywords: Bolsa Família Program. Right to education. Quality conditions. Educational politics.

\title{
Introdução
}

O PNE, aprovado pela Lei ${ }^{\circ}$ 13.005/2014 (BRASIL, 2014a), faz referência oito vezes à necessidade de reconhecimento das desigualdades de acesso ao sistema escolar decorrentes da renda. Entre estas, a meta 2, estratégia 4, é um bom exemplo da preocupação com uma perspectiva de inclusão ampla:

2.4) fortalecer o acompanhamento e o monitoramento do acesso, da permanência e do aproveitamento escolar dos beneficiários de programas de transferência de renda, bem como das situações de discriminação, preconceitos e violências na escola, visando ao estabelecimento de condições adequadas para o sucesso escolar dos(as) alunos(as), em colaboração com 
as famílias e com órgãos públicos de assistência social, saúde e proteção à infância, adolescência e juventude (BRASIL, 2014a).

O Programa Bolsa Família (PBF) não é, a rigor, um programa educacional, mas ao estabelecer a frequência escolar no Ensino Fundamental (EF) e Ensino Médio (EM) como uma condicionalidade, o programa passa a ter, além de implicações para as famílias, consequências para o poder público e para a política educacional. A própria legislação desenha o sentido dessas implicações, pois, para a efetivação do Programa, existem condicionalidades/compromissos assumidos tanto pelas famílias beneficiárias quanto pelo poder público. Por um lado, as famílias devem assumir e cumprir esses compromissos para continuar recebendo o benefício. Por outro, as condicionalidades responsabilizam o poder público pela oferta dos serviços públicos de saúde, educação e assistência social. Documento do Ministério do Desenvolvimento Social (MDS) esclarece esta pactuação: "Na educação, todas as crianças e adolescentes entre 6 e 15 anos devem estar devidamente matriculados e com frequência escolar mensal mínima de $85 \%$ da carga horária. Já os estudantes entre 16 e 17 anos devem ter frequência de, no mínimo, 75\%". (BRASIL, 2015).

Visto que a educação compõe o compromisso entre o poder público e as famílias, parece necessário compreender o sentido que a efetividade da política educacional toma para a garantia da oferta escolar. A capacidade do poder público, além de garantir de forma objetiva acesso à vaga na escola, também precisa incidir nas condições de frequência à escola, que têm implicações na permanência e no progresso do percurso escolar (FIGUEIREDO; FIGUEIREDO, 1986). O sentido dado pela política às condicionalidades ajuda a compor a compreensão de que essas são uma via de mão dupla ao responsabilizar a família, mas também ao poder público em relação à qualidade da oferta do serviço, nesse sentido, observa-se os objetivos delineados oficialmente no Programa:

[...] monitorar o cumprimento dos compromissos pelas famílias beneficiárias, como determina a legislação do programa; - responsabilizar o poder público pela garantia de acesso aos serviços e pela busca ativa das famílias mais vulneráveis; - identificar, nos casos de não cumprimento, as famílias em situação de maior vulnerabilidade e orientar ações do poder público para o acompanhamento dessas famílias (BRASIL, 2015).

Frente a essa leitura, compreender a política educacional, considerando o perfil do aluno atendido, é relevante. Para este exercício tomaremos um 
retrato da população escolar paranaense, no ano de 2014, a partir de dados de frequências escolares dos estudantes bolsistas do PBF, denominado de Banco de Dados do Sistema Presença (BRASIL, 2014c), que acompanha o cumprimento da condicionalidade no âmbito das escolas.

Cabe considerar que o Banco do Sistema Presença é um banco de dados administrativo, que objetiva acompanhar a condicionalidade de acesso ao benefício, assim, ao cotejá-lo com o Censo Escolar, algumas inconsistências se apresentaram, o que levou à perda de informações. Para a análise quantitativa, apresentada neste artigo, a preparação do banco de dados implicou em uma organização que assegurasse consistência para o emparelhamento das variáveis do Censo Escolar e do Banco do Sistema Presença. Como os dados do segundo são coletados mensalmente, optou-se por emparelhar os dados relativos ao mês da coleta do Censo Escolar - maio. No Banco do Sistema Presença, encontraram situações de estudantes sem a informação do código da escola e alguns casos de matrículas em escolas que não ofertam a série/ano informado para o aluno. Isso implicou em uma perda de cerca de $12 \%$ dos casos. Assim, o banco de dados emparelhado final é composto por informações de 225.170 estudantes beneficiários do PBF no EF, distribuídos em 5.049 escolas nos 399 municípios do Paraná. A Tabela 1 apresenta uma síntese dos dados disponíveis no banco de dados consolidado e os dados de beneficiários totais informados pelo MDS em 2014.

TABELA 1 - NÚMERO DE BENEFICIÁRIOS DO PBF NO PARANÁ, 2014.

\begin{tabular}{cccc}
\hline Beneficiários & $\begin{array}{c}\text { Número de } \\
\text { escolas }\end{array}$ & Total & Percentual \\
\hline Paraná & - & 1.452 .597 & \\
\hline $\begin{array}{c}\text { de 7 a 14 anos no Paraná } \\
\text { anos iniciais EF com informações no banco de } \\
\text { dados consolidado }\end{array}$ & 3147 & 113.829 & $24 \%$ \\
\hline $\begin{array}{c}\text { anos finais EF com informações no banco de } \\
\text { dados consolidado }\end{array}$ & 1902 & 111.341 & \\
\hline $\begin{array}{c}\text { EF total com informações no banco de dados } \\
\text { consolidado }\end{array}$ & 5049 & 225.170 & $63 \%$ \\
\hline
\end{tabular}

FONTE: MDS, Cadastro Único para Programas Sociais (CadÚnico), Folha de Pagamentos do Programa Bolsa Família (PBF), Banco de dados do Sistema Presença (BRASIL, 2014c).

Observe que no Paraná o MDS informou que o PBF beneficiava mais de 1 milhão de pessoas, entre estas $24 \%$ em idade de 7 a 14 anos. Ainda que o EF nesse período já fosse obrigatório a partir dos 6 anos, a informação dá um panorama aproximado da abrangência do Programa no estado. $\mathrm{O}$ banco de 
dados consolidado pela pesquisa contém informação para $63 \%$ dos estudantes beneficiários, ou seja, 225.170 estudantes.

Para análise, o artigo está organizado em três sessões: na primeira sessão, apresenta-se a distribuição dos estudantes beneficiários do PBF nos municípios paranaenses; na segunda, a análise propõe uma aproximação das condições de oferta das escolas onde há grande incidência de estudantes beneficiários desse Programa; a terceira sessão apresenta alguns desafios para a política educacional frente ao direito à educação.

\section{Os estudantes do EF beneficiários do Programa Bolsa Família no Paraná}

O Paraná tem 399 municípios que partilham o atendimento do EF com uma predominância de atendimento dos anos iniciais nas redes municipais e a predominância da oferta de anos finais na rede estadual de ensino. A participação da rede privada é menor que $15 \%$, e a rede federal têm menos de $1 \%$ da matrícula no EF, neste caso especialmente nos anos finais. Este desenho de repartição da matrícula tem relação com a forma como o regime de colaboração se constituiu historicamente no estado a partir de um processo de municipalização já efetivado no início dos anos 1990, este processo foi analisado em estudos de Santos (2003) e atualizado nos estudos de Zampiri (2014).

A Tabela 2 coteja o percentual de beneficiários por escola no Paraná com o perfil de desenvolvimento municipal medido pelo Índice de Desenvolvimento Humano Municipal (IDHM). Observa-se que o Programa de maneira geral tem chegado onde se espera que ele precisa chegar, ou seja, nos municípios com os níveis mais baixos de desenvolvimento humano. A correlação de Pearson entre percentual de beneficiários nos anos iniciais do EF foi de -0,532, e a mesma relação encontrada no caso dos anos finais foi de $-0,555$, evidenciando que o aumento do percentual de estudantes beneficiários do PBF encontra-se correlacionado com o baixo IDHM dos municípios.

Considerando que os estudantes estão distribuídos em diferentes redes de ensino e, por isso, submetidos a diferentes condições de oferta, cabe considerar mais detidamente esta distribuição. Entre os estudantes matriculados nos anos finais do EF, 17\% eram beneficiários do PBF em 2014 e, no caso dos estudantes matriculados nos anos iniciais, 14\% eram beneficiários. A Tabela 3 permite observar ainda que considerando apenas os dados de matrículas das escolas que constam no banco de dados consolidado na pesquisa, ou seja, o banco que 
TABELA 2 - CORRELAÇÃO DE PEARSON - IDHM E PERCENTUAL DE ESTUDANTES BOLSISTA, PARANÁ, 2014.

\begin{tabular}{l|c|c|c}
\hline & IDHM & $\begin{array}{c}\text { Percentual beneficiários } \\
\text { PBF anos iniciais }\end{array}$ & $\begin{array}{c}\text { Percentual beneficiários } \\
\text { PBF anos finais }\end{array}$ \\
\hline Correlação de Pearson & 1 & $-0,532^{* *}$ & $-0,555^{* *}$ \\
\hline Significância (base 1) & &, 000 &, 000 \\
\hline Número & 5049 & 3147 & 1902 \\
\hline **. Correlação é significativa & & \\
até o nível 0,01 (base 1). & & & \\
\hline
\end{tabular}

FONTE: Banco Sistema Presença (BRASIL, 2014c); Atlas do Desenvolvimento Humano (2010). Dados trabalhados pelos autores.

contém apenas as escolas em que foram informados estudantes beneficiários do PBF com código da escola consistente, a proporção é um pouco maior, porém coerente com a proporção comparativa às matrículas.

Dados do MDS informam que no Brasil havia aproximadamente 11 milhões de beneficiários do PBF na idade de 7 a 14, portanto na idade de EF, considerando o total de aproximadamente 28 milhões de matrículas em 2014 (INEP, 2014), constata-se que $40 \%$ da população escolar brasileira era beneficiária. O Paraná apresenta uma participação um pouco menor de beneficiários o que é coerente com o perfil de desenvolvimento do estado.

TABELA 3 -DISTRIBUIÇÃO DOS ESTUDANTES BENEFICIÁRIOS DO PROGRAMA BOLSA FAMÍLIA POR ETAPA DE ENSINO NO TOTAL DOS MUNICÍPIOS - PARANÁ, 2014.

\begin{tabular}{ccc}
\hline & Anos Iniciais & Anos finais \\
\hline Matrículas informadas no Censo Escolar 2014 & 802.424 & 673.722 \\
\hline $\begin{array}{c}\text { Matrículas informadas nas escolas no Banco de Dados } \\
\text { Consolidado }\end{array}$ & 685.505 & 595.030 \\
\hline Beneficiários do PBF & 113.829 & 111.341 \\
\hline $\begin{array}{c}\text { Percentual de beneficiários em relação ao total da matrícula } \\
\text { Percentual de beneficiários em relação às matrículas nas } \\
\text { escolas no Banco de Dados Consolidado }\end{array}$ & $14 \%$ & $17 \%$ \\
\hline
\end{tabular}

FONTE: Banco Sistema Presença (BRASIL, 2014c); INEP (2014). Dados trabalhados pelos autores.

Para avançar no debate sobre as condições de oferta das escolas para a população pobre, é preciso localizar os estudantes nas redes de ensino. A partir daqui, vamos trabalhar apenas com os dados das escolas presentes no Banco do Sistema Presença Consolidado. 
A forma que o regime de colaboração assume, no estado do Paraná, implica divisão da oferta do EF com os anos iniciais, sob responsabilidade predominante das redes municipais e os anos finais predominantemente do estado. A Tabela 4 apresenta a distribuição dos estudantes nas redes estadual e municipal e a localização das matrículas. Observe que a rede estadual concentra beneficiários do PBF nos anos finais do EF, e, entre estes, apenas $6,1 \%$ em escolas na zona rural. Na rede municipal, predominam os beneficiários com matrícula nos anos iniciais, porém há 84 beneficiários em uma escola de EF da capital que ainda oferta anos finais do EF. Há no caso das redes municipais uma participação maior de estudantes beneficiários em escolas localizadas na zona rural.

\section{TABELA 4 -BENEFICIÁRIOS DO PBF EM ESCOLAS DO PARANÁ, POR} DEPENDÊNCIA ADMINISTRATIVA E LOCALIZAÇÃO, 2014.

\begin{tabular}{|c|c|c|c|c|c|c|c|c|}
\hline & \multicolumn{4}{|c|}{ Estadual } & \multicolumn{4}{|c|}{ Municipal } \\
\hline & \multicolumn{2}{|c|}{ Urbana } & \multicolumn{2}{|c|}{ Rural } & \multicolumn{2}{|c|}{ Urbana } & \multicolumn{2}{|c|}{ Rural } \\
\hline & Total & $\%$ & Total & $\%$ & Total & $\%$ & Total & $\%$ \\
\hline $\begin{array}{c}\mathrm{N}^{\circ} \text { de matrículas nos } \\
\text { AI do EF }\end{array}$ & 636 & $24,9 \%$ & 1.920 & $75,1 \%$ & 626.230 & $91,7 \%$ & 56.719 & $8,3 \%$ \\
\hline Beneficiários AI EF & . & . & . & . & 99.370 & $87,3 \%$ & 14.459 & $12,7 \%$ \\
\hline $\begin{array}{c}\mathrm{N}^{\circ} \text { de matrículas nos } \\
\mathrm{AF} \text { do EF }\end{array}$ & 544.976 & $93,9 \%$ & 35.355 & $6,1 \%$ & 13.479 & $91,7 \%$ & 1.220 & $8,3 \%$ \\
\hline Beneficiários AF EF & 99.854 & $89,8 \%$ & 11.403 & $10,2 \%$ & 84 & $100,0 \%$ & . & . \\
\hline
\end{tabular}

FONTE: Banco Sistema Presença (BRASIL, 2014c); Censo Escolar (INEP, 2014). Dados trabalhados pelos autores.

Os elementos apresentados até aqui retratam de maneira muito geral onde estão os estudantes beneficiários do PBF no estado do Paraná. Quase 20\% dos estudantes matriculados no $\mathrm{EF}$, no ano de 2014, no estado, eram beneficiários do referido programa. Estes estudantes estão divididos entre as redes municipais e a rede estadual ${ }^{1}$ de forma coerente com o perfil da matrícula no estado. São estudantes predominantemente da zona urbana e concentram-se em municípios com baixo desenvolvimento humano, ainda que estejam presentes no conjunto do estado. A Figura 1 a seguir ilustra a tendência de que quanto menor o IDHM do município maior o número de beneficiários.

1 A rede federal conta com um pequeno número de beneficiários, que somam 45 e, a rede privada, 3590. Como nosso objetivo é olhar a ação do poder público, optamos por não analisar neste momento a rede privada. A rede federal não foi contabilizada, porque é quase inexpressiva, em termos de matrículas e até mesmo de beneficiários e as condições de suas escolas diferem, em muito, da realidade das redes estaduais e municipais do país. 
FIGURA 1 - PERCENTUAL DE BENEFICIÁRIOS DO PROGRAMA BOLSA FAMÍLIA E IDHM SEGUNDO O MUNICÍPIO - PARANÁ - 2014

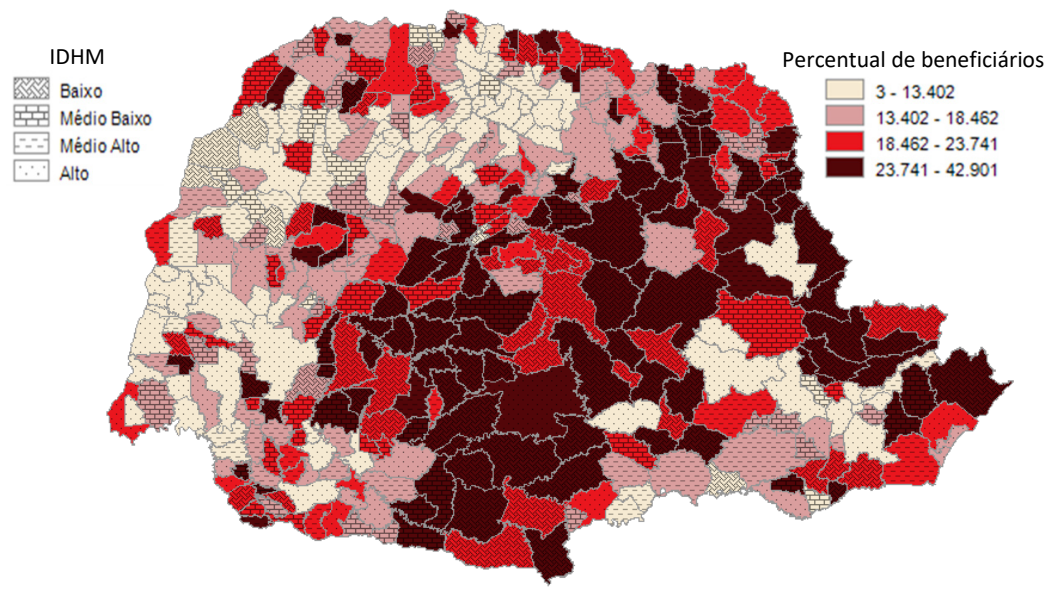

FONTE: Banco Sistema Presença (BRASIL, 2014c); Atlas do Desenvolvimento Humano (2010). Dados trabalhados pelos autores.

Ao que parece, em termos de política social, em geral, o PBF tem atingido seus objetivos, estando mais presente justamente naqueles municípios onde a situação de desenvolvimento humano é mais baixa. Diante desse quadro, cabe analisar se as políticas educacionais também têm sido efetivas no sentido de garantir condições de qualidade para todos, mas especialmente para os estudantes mais pobres. Nesse sentido, questiona-se qual a condição de oferta das escolas que os estudantes pobres têm frequentado no Paraná?

\section{As condições de oferta das escolas paranaenses e os estudantes beneficiários do Programa Bolsa Família}

O conceito de condições de qualidade na educação tem se consolidado na literatura educacional (CAMARGO et al., 2006; DOURADO; OLIVEIRA, 2009) como expressão da ideia de que há elementos essenciais que constituem o cotidiano das escolas e que se caracterizam como condições básicas para a construção da qualidade na educação. $\mathrm{O}$ conceito de condições de qualidade sintetiza a preocupação com o fato de que a qualidade na educação é mais ampla que a materialização das condições de oferta, porém, não pode prescindir de 
elementos objetivos e quantificáveis para dar suporte à construção do processo pedagógico escolar.

Nessa perspectiva, tomam-se aqui as variáveis de condições de oferta relativas às condições de trabalho dos professores e infraestrutura escolar para uma aproximação à ideia de que a superação das desigualdades educacionais no país implica na inclusão dos estudantes pobres na escola, mas com oferta de condições de qualidade que permitam trajetórias plenas de desenvolvimento humano para estes sujeitos. A ideia de que "a educação não distribui apenas o futuro aos indivíduos, mas seu presente" (WALZER, 2003, p. 271) exige que o conjunto da experiência escolar seja inclusiva.

Interessa neste artigo mapear elementos de condições de oferta que sejam passíveis de controle/melhoria pelo poder público, dada a compreensão de que a condicionalidade do PBF para o beneficiário deve conter uma condicionalidade ao próprio poder público, como responsável pela efetividade da oferta educacional, não apenas na garantia do acesso à escola e do controle da sua frequência.

Para melhor visualização das análises, organizamos as escolas em quatro faixas de percentual de estudantes beneficiários do PBF matriculados, considerando: baixa presença de beneficiários de até $11 \%$ de bolsistas; média-baixa de $11 \%$ a $18 \%$; média de $18 \%$ a $27 \%$; e, alta, quando havia mais de $27 \%$ de bolsistas. O Gráfico 1 a seguir ilustra a pertinência dessas faixas para o caso específico do estado do Paraná:

\section{GRÁFICO 1 -DISTRIBUIÇÃO DO PERCENTUAL DE ESTUDANTES DO PBF NAS ESCOLAS DO PARANÁ, 2014.}

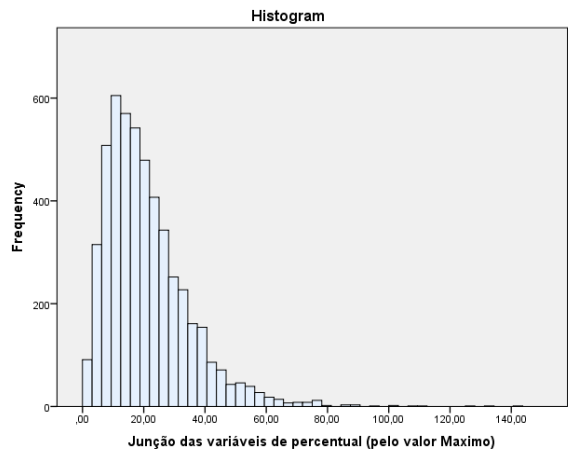

FONTE: Banco Sistema Presença (BRASIL, 2014c); Censo Escolar (INEP, 2014).

A partir desse ponto, portanto, apresentar-se-ão as análises comparativas em relação às faixas de presença de estudantes do PBF, cotejados com as va- 
riáveis de condições de oferta. Um primeiro elemento para pensar quanto às condições de oferta que estão sendo asseguradas para os estudantes pobres no Paraná será a condição de trabalho do professor. Nesse caso cabe observar o tipo de contrato do professor, considerando o percentual de estudantes beneficiários do PBF na escola e a dependência administrativa.

A Tabela 5 apresenta as condições de vínculo empregatício dos professores, considerando a faixa de estudantes beneficiários por escolas das duas dependências administrativas públicas em questão.

\section{TABELA 5 - VÍNCULOS DOS PROFESSSORES POR DEPENDÊNCIA ADMI- NISTRATIVA E FAIXA DO PERCENTUAL DE ESTUDANTES DO BOLSA FAMÍLIA EM 2014.}

\begin{tabular}{c|c|c|c|c|c}
\hline \multirow{2}{*}{$\begin{array}{c}\text { Tipo de contrato dos } \\
\text { professores }\end{array}$} & \multicolumn{2}{c|}{ Estadual } & \multicolumn{2}{c}{ Municipal } \\
\cline { 3 - 6 } \multicolumn{2}{c|}{} & Concursados & $\begin{array}{c}\text { Contrato } \\
\text { temporário }\end{array}$ & Concursados & $\begin{array}{c}\text { Contrato } \\
\text { temporário }\end{array}$ \\
\cline { 2 - 6 } & \multicolumn{3}{|c}{ Percentual Médio } \\
\hline \multirow{4}{*}{\begin{tabular}{c} 
Faixas \\
\cline { 2 - 6 }
\end{tabular}} & até 11\% & 61,69 & 38,62 & 94,64 & 14,74 \\
\cline { 2 - 6 } & de 11\% a 18\% & 56,67 & 43,52 & 91,75 & 18,98 \\
\cline { 2 - 6 } & de 18\% a 27\% & 55,73 & 45,48 & 90,32 & 24,71 \\
\cline { 2 - 6 } & mais de 27\% & 50,01 & 52,80 & 88,24 & 33,05 \\
\hline
\end{tabular}

Fonte: Banco Sistema Presença (BRASIL, 2014c); Censo Escolar (INEP, 2014). Dados trabalhados pelos autores.

Observe que o percentual médio de professores concursados é mais alto nas redes municipais que na rede estadual. Porém, a distribuição dos professores nas escolas por faixa de beneficiários do PBF deixa explícito que aquelas escolas com mais de $27 \%$ de estudantes pobres têm um percentual maior de professores temporários nos dois casos. Na rede estadual, este número chega a $52,8 \%$, enquanto, nas redes municipais, o percentual médio chega a $33,3 \%$. A Correlação de Pearson entre as variáveis percentual de estudantes beneficiários do PBF na escola e o percentual de professores temporários é 0,292. Ainda que seja uma correlação fraca, o vetor positivo na correlação significa que ao crescer o percentual de professores temporários atuando na escola, há maior presença de estudantes do PBF.

Oliveira (2010), discutindo o lugar da profissão docente no contexto de reformas educacionais, evidência que essas, contraditoriamente, colocam o professor no centro das preocupações da política educacional, ao mesmo tempo em que o lugar do professor é marcado por uma diversidade de composições que compromete o sentido da própria profissão. 
O professor, diante das variadas funções que a escola pública assume, tem de responder a exigências para as quais não se sente preparado. Muitas vezes os trabalhadores docentes são obrigados a desempenharem funções de agente público, assistente social, enfermeiro, psicólogo, entre outras. Tais exigências contribuem para um sentimento de desprofissionalização, de perda de identidade, da constatação de que ensinar às vezes não é o mais importante. (OLIVEIRA, 2010, p. 24).

A preocupação expressa por Oliveira (2010) ajuda a discutir os problemas dos inúmeros vínculos a que os professores estão submetidos. Se o contexto de inserção do professor na escola é marcado por uma ampliação das demandas sobre sua obrigação como agente público, a existência de vínculos frágeis de contratação compromete mais ainda a possibilidade da realização do trabalho escolar. Assim, o cenário de que as escolas com mais estudantes beneficiários do PBF constituem-se por um número maior de professores com vínculo temporário, amplia as dificuldades para que a construção do trabalho pedagógico garanta ao professor o controle sobre seu próprio trabalho e a possibilidade de articulação coletiva, elementos fundamentais para construir um sentido de inclusão para estudantes pobres.

Outro fator importante, no que se refere à condição de oferta, diz respeito à formação dos docentes. Para tal análise, estamos considerando que professores com escolaridade igual ou inferior ao Ensino Médio Regular e aqueles que têm formação no Ensino Superior, mas não possuem Licenciatura, não possuem formação mínima necessária para atuar no EF. A formação em Nível Médio na Modalidade Normal é aceita para os cinco primeiros anos do EF e a Licenciatura é a formação mínima para atuação docente nos anos finais desta etapa conforme definição da Lei nº 9394/1996 (BRASIL, 1996).

Na Tabela 6, ao observar os dados das escolas paranaenses, onde estão distribuídos os estudantes do PBF, é possível perceber uma tendência de que quanto maior o percentual de beneficiários maior o número de professores sem a formação mínima nas duas etapas de ensino, e também maior incidência nas séries iniciais, onde inclusive a exigência de formação mínima ainda é, de pelo menos, a modalidade normal de nível médio. Neste caso, na faixa com alto percentual de estudantes do PBF, o percentual de professores com formação mínima chegou a $12,89 \%$. 
TABELA 6 -FORMAÇÃO DOS PROFESSORES POR DEPENDÊNCIA ADMINISTRATIVA E FAIXA DO PERCENTUAL DE ESTUDANTES DO PROGRAMA BOLSA FAMÍLIA EM 2014, PARANÁ.

\begin{tabular}{c|c|c|c|c}
\hline $\begin{array}{c}\text { Faixa de percentual } \\
\text { de beneficiários do } \\
\text { PBF na escola }\end{array}$ & \multicolumn{2}{|c|}{ EF Séries iniciais } & \multicolumn{2}{c}{ EF Séries finais } \\
\cline { 2 - 5 } & $\begin{array}{c}\text { \% médio de } \\
\text { Professores } \\
\text { sem formação } \\
\text { mínima }\end{array}$ & $\begin{array}{c}\text { \% médio de } \\
\text { Professores } \\
\text { com formação } \\
\text { mínima }\end{array}$ & $\begin{array}{c}\text { \% médio de } \\
\text { Professores } \\
\text { sem formação } \\
\text { mínima }\end{array}$ & $\begin{array}{c}\text { \% médio de } \\
\text { Professores } \\
\text { com formação } \\
\text { mínima }\end{array}$ \\
\hline até $11 \%$ & 5,51 & 94,61 & 4,36 & 95,70 \\
\hline de $11 \%$ a $18 \%$ & 7,69 & 92,93 & 5,72 & 94,28 \\
\hline de $18 \%$ a $27 \%$ & 9,16 & 91,29 & 6,47 & 93,53 \\
\hline mais de $27 \%$ & 12,89 & 89,75 & 7,43 & 92,57 \\
\hline
\end{tabular}

FONTE: Banco Sistema Presença (BRASIL, 2014c); Censo Escolar (INEP, 2014).

Cabe observar agora, entre os professores com a formação mínima, como estes se distribuem nas etapas de EF, dado que são exigências diferentes. Observa-se na Tabela 7 que se confirma a tendência de um percentual maior de professores com a formação mínima nas escolas com maior presença de beneficiários do PBF.

TABELA 7 -FORMAÇÃO MÍNIMA DOS PROFESSORES POR ETAPA DE ENSINO E FAIXA DO PERCENTUAL DE ESTUDANTES DO PROGRAMA BOLSA FAMÍLIA EM 2014, PARANÁ.

\begin{tabular}{c|c|c}
\hline $\begin{array}{c}\text { Faixa de percentual } \\
\text { de beneficiários } \\
\text { do PBF na escola } \\
\text { (quartis) }\end{array}$ & $\begin{array}{c}\text { EF séries iniciais } \\
\text { Percentual médio de professores } \\
\text { com formação de Nível Médio } \\
\text { Modalidade Normal }\end{array}$ & $\begin{array}{c}\text { Percentual médio de professores } \\
\text { com formação em Licenciatura } \\
\text { ou Complementação Pedagógica }\end{array}$ \\
\hline até 11\% & 10,26 & 95,66 \\
\hline de 11\% a 18\% & 13,29 & 94,20 \\
\hline de 18\% a 27\% & 18,61 & 93,52 \\
\hline mais de 27\% & 26,05 & 92,44 \\
\hline
\end{tabular}

Fonte: Banco Sistema Presença (BRASIL, 2014c); Censo Escolar (INEP, 2014).

Para avançar na discussão de formação, optou-se por analisar a formação em nível de pós-graduação dos profissionais da Educação Básica. Tal opção relaciona-se com o cenário de metas do PNE (BRASIL, 2014a) que estabelece, na meta 16 , o horizonte de formação de pós-graduação para, pelo menos, $50 \%$ dos professores da Educação Básica. O diagnóstico apresentado pelo INEP informa que: “[...] a especialização é a titulação mais frequentemente obtida pelos professores. Em 2013, 28,9\% dos professores possuíam essa titulação. 
Mestrado e doutorado possuem menor participação no indicador, uma vez que seus índices de ocorrência são bastante reduzidos: $1,1 \%$ e $0,1 \%$, respectivamente". (INEP, 2015, p. 280).

Com os dados da Tabela 8, pode-se observar a condição dos professores que têm ensino superior completo e, portanto, podem cursar pós-graduação. A mesma tendência se repete na comparação entre as faixas de beneficiários. Cabe destacar que, no caso paranaense, em todos as faixas já se cumpre a meta do PNE, pois, mesmo nas séries iniciais na faixa com mais de $27 \%$ de beneficiários, há mais de $50 \%$ dos professores com especialização. Entretanto, cabe considerar as condições de equidade da oferta no âmbito da rede de ensino, uma vez que a qualidade é sempre um conceito historicamente situado. Assim, ainda que o indicador de formação de professores nas redes públicas municipais e estaduais do Paraná seja interessante ao superar a meta do PNE, mantém desigualdades de oferta internas no estado e que não são aleatórias, são efetivamente em prejuízo dos estudantes pobres. A formação nos níveis de mestrado e doutorado, assim como no Brasil, é menor que $2 \%$ no conjunto das redes municipais e estadual do Paraná.

TABELA 8 - PERCENTUAL DE PROFESSORES COM FORMAÇÃO EM ESPECIALIZAÇÃO, POR ETAPA DE ENSINO E FAIXA DE ESTUDANTES DO PROGRAMA BOLSA FAMÍLIA, 2014.

\begin{tabular}{c|c|c|c|c}
\hline $\begin{array}{c}\text { Faixa de percentual } \\
\text { de beneficiários } \\
\text { do PBF na escola } \\
\text { (quartis) }\end{array}$ & $\begin{array}{c}\text { EF Séries iniciais } \\
\begin{array}{c}\text { Especialização } \\
\text { sobre o total de } \\
\text { professores da } \\
\text { escola }\end{array}\end{array}$ & $\begin{array}{c}\text { Especialização } \\
\text { sobre o total de } \\
\text { professores com } \\
\text { Ensino Superior }\end{array}$ & $\begin{array}{c}\text { Especialização } \\
\text { sobre o total de } \\
\text { professores da } \\
\text { escola }\end{array}$ & $\begin{array}{c}\text { Especialização } \\
\text { sobre o total de } \\
\text { professores com } \\
\text { Ensino Superior }\end{array}$ \\
\cline { 2 - 5 } & Média & Média & Média & Média \\
\hline até 11\% & 66,14 & 70,77 & 83,37 & 85,53 \\
\hline de 11\% a 18\% & 64,09 & 70,89 & 80,53 & 83,62 \\
\hline de 18\% a 27\% & 62,01 & 71,33 & 81,86 & 85,27 \\
\hline mais de 27\% & 53,28 & 63,04 & 81,38 & 85,53 \\
\hline
\end{tabular}

FONTE: Banco Sistema Presença (BRASIL, 2014c); Censo Escolar (INEP, 2014).

O segundo bloco de questões quanto às condições de oferta, referente a aspectos de infraestrutura básica para o trabalho pedagógico escolar - biblioteca ou sala de leitura, quadra de esportes, acesso à Internet Banda Larga e laboratório de informática. A escolha de elementos para análise das condições de infraestrutura é sempre um desafio, entre a opção de aspectos básicos de vida, como acesso à água, ao esgoto etc., e, elementos mais diretamente relacionados à possibilidade de desenvolvimento de um trabalho pedagógico que responda 
ao tempo presente. A seleção das variáveis aqui apresentadas tentou estabelecer a segunda direção como preocupação.

Especificamente quanto às condições de qualidade no ambiente escolar, a Tabela 9 apresenta a síntese das condições de oferta. Observa-se que, de maneira geral, as escolas municipais apresentam o menor percentual de presença dos elementos selecionados, mas, sobretudo, é preocupante que os piores descritores de oferta estão nas faixas de maior percentual de beneficiários do PBF. As únicas duas variáveis em que as redes municipais superam a estadual são a sala de leitura e a Internet Banda Larga. No caso da sala de leitura, essa é uma solução mais usual para as escolas dos anos iniciais que não têm biblioteca, isso pode explicar a predominância desta nas redes municipais. De toda forma, há um número pequeno de escolas que tem este equipamento em geral. No caso da banda larga, parece ser um indicador favorável, porém há que se considerar que na rede estadual praticamente $100 \%$ das escolas têm algum acesso à internet.

TABELA 9 - PERCENTUAL DE ESCOLAS COM ELEMENTOS INFRAESTRUTURAIS SELECIONADOS POR FAIXA DE BENEFICIÁRIOS E DEPENDÊNCIA ADMINISTRATIVA, PARANÁ, 2014

\begin{tabular}{c|c|c|c|c|c|c|c|c}
\hline \multirow{4}{*}{ DA } & Faixa BPBF & $\begin{array}{c}\text { Biblio- } \\
\text { teca }\end{array}$ & $\begin{array}{c}\text { Sala de } \\
\text { Leitura }\end{array}$ & $\begin{array}{c}\text { Quadra } \\
\text { Esportes } \\
\text { Descoberta }\end{array}$ & $\begin{array}{c}\text { Quadra } \\
\text { Esportes } \\
\text { Coberta }\end{array}$ & $\begin{array}{c}\text { Lab. } \\
\text { Infor- } \\
\text { mática }\end{array}$ & Internet & $\begin{array}{c}\text { Banda } \\
\text { Larga }\end{array}$ \\
\hline \multirow{5}{*}{ Estadual } & até $11 \%$ & $94 \%$ & $5 \%$ & $47 \%$ & $75 \%$ & $96 \%$ & $100 \%$ & $88 \%$ \\
\cline { 2 - 9 } & de $11 \%$ a $18 \%$ & $93 \%$ & $8 \%$ & $41 \%$ & $82 \%$ & $96 \%$ & $100 \%$ & $86 \%$ \\
\cline { 2 - 9 } & de $18 \%$ a $27 \%$ & $94 \%$ & $6 \%$ & $35 \%$ & $81 \%$ & $95 \%$ & $99 \%$ & $79 \%$ \\
\cline { 2 - 9 } & mais de $27 \%$ & $86 \%$ & $6 \%$ & $26 \%$ & $74 \%$ & $92 \%$ & $99 \%$ & $62 \%$ \\
\cline { 2 - 9 } & Total & $92 \%$ & $6 \%$ & $37 \%$ & $78 \%$ & $95 \%$ & $100 \%$ & $78 \%$ \\
\hline \multirow{7}{*}{ Municipal } & até $11 \%$ & $73 \%$ & $10 \%$ & $24 \%$ & $63 \%$ & $84 \%$ & $96 \%$ & $91 \%$ \\
\cline { 2 - 9 } & de $11 \%$ a $18 \%$ & $64 \%$ & $11 \%$ & $23 \%$ & $53 \%$ & $78 \%$ & $93 \%$ & $84 \%$ \\
\cline { 2 - 9 } & de $18 \%$ a $27 \%$ & $57 \%$ & $9 \%$ & $24 \%$ & $41 \%$ & $68 \%$ & $88 \%$ & $80 \%$ \\
\cline { 2 - 9 } & mais de $27 \%$ & $39 \%$ & $9 \%$ & $14 \%$ & $30 \%$ & $54 \%$ & $67 \%$ & $75 \%$ \\
\cline { 2 - 9 } & Total & $59 \%$ & $10 \%$ & $21 \%$ & $47 \%$ & $71 \%$ & $87 \%$ & $83 \%$ \\
\hline
\end{tabular}

Fonte: Banco Sistema Presença (BRASIL, 2014c); Censo Escolar (INEP, 2014).

Cada um desses elementos, certamente, pode conter especificidades para a análise. Schneider (2014), ao analisar as condições materiais das escolas brasileiras, já chamava a atenção para a desigualdade de condições da dependência municipal. No caso paranaense, onde estes entes federados são responsáveis predominantemente pelas séries iniciais, é preocupante constatar que o ingresso da população na escola de EF se faça em condições, em geral, mais precárias. De certa forma, ao sobreviver ao longo do percurso escolar, o estudante poderia se beneficiar de melhores condições de oferta ao chegar a rede estadual. 
Pode-se ainda ser considerada certa especificidade, por exemplo, nas condições de quadra de esporte, que nas séries iniciais podem estar menos presentes devido à ênfase em atividades físicas de recreação. De toda forma, essa é uma variável que demanda também considerar localização urbana e rural para dimensionar os contornos específicos do problema de ausência desta instalação nas escolas. Ao observar o percentual de escolas com quadra de esportes coberta na zona urbana, a cobertura é de $67,3 \%$, enquanto na zona rural é de $34,4 \%$, sendo que tais percentuais decrescem se considerar a faixa de estudantes beneficiários do $\mathrm{PBF}$.

As variáveis banda larga e laboratório de informática novamente podem ter relação com a fase do EF. A cobertura de banda larga no conjunto das redes e nas faixas com menor número de estudantes do PBF é maior que $90 \%$, o que pode significar que, mesmo sem laboratório, a escola tem possibilidade de acesso à internet. Porém a situação é mais precária nas faixas com mais estudantes do PBF. De toda forma, preocupa a existência de banda larga apenas para uso administrativo, pois, se o único ponto de acesso à internet na escola for a secretaria, esta tenderá a ter pouco impacto no trabalho pedagógico.

\section{Desafios para as políticas educacionais: a título de considerações finais}

Pensar os desafios para a efetividade do direito à educação para as crianças pobres requer retomarmos um dos elementos definidos entre os objetivos da política do PBF, o programa implica responsabilizar o poder público pela garantia de acesso aos serviços públicos. Essa garantia de acesso precisa ser mais complexa que apenas o fornecimento de qualquer vaga no sistema escolar e o controle da frequência.

Se o sentido da igualdade de acesso à escola, que também é princípio constitucional, colocar-se de maneira rigorosa, a correlação entre inclusão de estudantes bolsistas do PBF com professores em contrato temporário, com formação mais restrita e pouca estrutura escolar que possibilite o desenvolvimento do trabalho escolar pode estar constituindo um descumprimento da condicionalidade referente ao poder público.

O estudo de Schefer (2014), sobre a relação dos professores com estudantes beneficiários do PBF, revela, no cotidiano de uma escola gaúcha, o peso que o preconceito com os sujeitos assume na escola e problematiza o quanto esta inclusão tem sido permeada por exclusões. Pires (2013), a partir de estudo de 
efeitos do PBF sobre as famílias, argumenta que, mais do que o sucesso escolar, a condicionalidade pode se articular com uma relação de pertencimento e reconhecimento social ao poder acessar os serviços públicos. O mesmo autor pondera que para isso a qualidade do serviço público ofertado precisa garantir a inclusão.

Parece que as características encontradas no Paraná, quanto às condições de oferta das escolas em que estão as crianças beneficiárias do PBF, podem estar reproduzindo os problemas à medida que se inclui estes sujeitos, mas com baixa condição da política educacional efetivamente cumprir seu papel.

É necessário chamar atenção para o fato de que, além das desigualdades entre as diversas redes educacionais já analisadas por diversos autores como Davies (2006) e Cruz (2009), há muita diferença entre as escolas que são de responsabilidade do mesmo ente federativo, e, em geral, essas diferenças de condições de oferta educacional tendem a reforçar as desigualdades sociais, políticas e econômicas. Walzer, ao pensar a ideia de justiça social na educação, alerta que há uma distribuição dos alunos dentro das escolas públicas e que essa não se dá de forma aleatória, segundo o autor "[...], não são apenas vagas que são distribuídas para as crianças, mas as próprias crianças são distribuídas entre as vagas disponíveis. [...]. Quem vai para a escola com quem? É uma questão distributiva em dois sentidos". (WALZER, 2003, p. 293).

Ao que parece, ainda que o PBF venha se consolidando como um programa que tem auxiliado na permanência dos estudantes na escola, há medida que garante à família um suporte econômico, essas ações precisam estar ancoradas com a garantia de outros serviços públicos. No caso da educação, garantir a plena efetivação do direito implica em reconhecer as diferenças e trabalhar no sentido de superá-las, tornando a escola realmente justa.

\section{REFERÊNCIAS}

ATLAS DO DESENVOLVIMENTO HUMANO. 2010. Disponível em: <http://www. atlasbrasil.org.br/2013/>. Acesso em: 12 fev. 2016.

BRASIL. Lei no 9394, de 20 de dezembro de 1996. Estabelece Diretrizes e Bases da Educação Nacional. Diário Oficial da União, Brasília, DF, 23 dez. 1996. Disponível em: <http://www.planalto.gov.br/ccivil_03/leis/L9394.htm>. Acesso em 14 jul. 2016.

BRASIL. Lei n 13005, de 24 de junho de 2014. Aprova o Plano Nacional de Educação - PNE e dá outras providências. Diário Oficial da União, Brasília, DF, Edição Extra, 26 
jun. 2014a. Disponível em: http://www.planalto.gov.br/ccivil_03/_ato2011-2014/2014/ lei/113005.htm. Acesso em: 14 jul. 2016.

BRASIL. Ministério do Desenvolvimento Social e Combate à Fome. Bolsa Família Brasília, 2015. Disponível em: <http://www.mds.gov.br/bolsafamilia>. Acesso em: 10 mar. 2015.

BRASIL. Ministério do Desenvolvimento Social e Combate à Fome. DataSOCIAL: Quantidade de beneficiários do Programa Bolsa Família segundo idade. Brasília, 2014b. Disponível em: <http://aplicacoes.mds.gov.br/sagi-ata/METRO/metro_ds.php?p_ id=74\&p_ibge=41\&p_geo=0>. Acesso em: 14 jul. 2016.

BRASIL. Ministério da Educação. Banco Sistema Presença. Brasília, 2014c. Disponível em: <http://frequenciaescolarpbf.mec.gov.br/presenca/controller/login/efetuarLogin. php>. Acesso em: 12 fev. 2016.

CAMARGO, R. B. de et al. Relatório de Pesquisa: Problematização do conceito de qualidade presente na pesquisa custo-aluno-ano em escolas de Educação Básica que oferecem condições para a oferta de um ensino de qualidade. Brasília: INEP/MEC, 2006.

CRUZ, R. E. da. Pacto federativo e financiamento da educação: a função supletiva e redistributiva da União - o FNDE em destaque. Tese (Doutorado em Educação) - Faculdade de Educação, Universidade de São Paulo, São Paulo. 2009.

DAVIES, N. Fundef: Solução ou remendo para o financiamento da educação básica? In: GOUVEIA, A. B; SOUZA, A. R.; TAVARES, T.M. Conversas sobre financiamento da educação no Brasil. Curitiba: Editora UFPR, 2006.

DOURADO, L. F.; OLIVEIRA, J. F. de. A qualidade da educação: perspectivas e desafios. Cadernos Cedes, Campinas (SP), vol. 29, n. 78, p. 201-215, maio/ago. 2009.

FIGUEIREDO, M. F.; FIGUEIREDO, A. M. C. Avaliação política e avaliação de política: um quadro teórico de referência. Análise e Conjuntura, Belo Horizonte (MG), p. 107-127, set./dez. 1986.

INSTITUTO NACIONAL DE ESTUDOS E PESQUISAS EDUCACIONAIS ANISIO TEIXEIRA (INEP). Plano Nacional de Educação - PNE 2014-2024: Linha de Base. Brasília: INEP, 2015.

INSTITUTO NACIONAL DE ESTUDOS E PESQUISAS EDUCACIONAIS ANISIO TEIXEIRA (INEP). Censo Escolar 2014. Microdados 2014. Disponível em: <http:// portal.inep.gov.br/basica-levantamentos-acessar>. Acesso em: 05 mar. 2016.

OLIVEIRA, D. A. Os trabalhadores da Educação e a construção política da profissão docente no Brasil. Educar em Revista, Curitiba (PR), edição especial, n. 1, p. 17-35, 2010.

PIRES, A. Afinal para que servem as condicionalidades em educação do Programa Bolsa Família. Ensaio: Avaliação de Políticas Públicas em educação, v. 1, n. 80, p. 513-531, set./dez. 2013. 
SANTOS, J. M. T. P. O processo de municipalização no estado do Paraná. Educar em revista, Curitiba, v. 22, p. 257-279, 2003.

SCHEFER, M. C. Relações periféricas na escola: incumbências e sucumbências do programa bolsa família. Educação. Unisinos, São Leopoldo, RS, v. 18, n. 2, p. 150-156, maio/ago. 2014.

SCHNEIDER, G. As ações do governo federal no âmbito das condições materiais e estruturais da escola: uma problematização a partir do conceito de justiça social. Tese (Doutorado em Educação) - Setor de Educação, Universidade Federal do Paraná, Curitiba, 2014.

WALZER, M. Esferas da Justiça: uma defesa do pluralismo e da igualdade. São Paulo: Martins Fontes, 2003.

ZAMPIRI, M. A disformidade no desenho da oferta educacional e a fragilização do direito à educação: um panorama da oferta de matrículas de ensino fundamental no Brasil. Tese (Doutorado em Educação) - Setor de Educação, Universidade Federal do Paraná, Curitiba. 2014.

Texto recebido em 24 de março de 2017. Texto aprovado em 12 de abril de 2017. 